\title{
Chemical Restraint
}

National Cancer Institute

\section{Source}

National Cancer Institute. Chemical Restraint. NCI Thesaurus. Code C158343.

A chemical substance that is administered in order to restrict movement. 